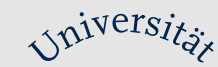

- $v_{\sigma_{s}}$ 监命耑

Humanwissenschaftliche Fakultät

Andrew Radford | Claudia Felser | Oliver Boxell

\title{
Preposition copying and pruning in present-day English
}

Suggested citation referring to the original publication:

English Language and Linguistics 16 (2012) 3, pp. 403-426

DOI https://doi.org/10.1017/S1360674312000172

ISSN (print) 1360-6743

ISSN (online) 1469-4379

Postprint archived at the Institutional Repository of the Potsdam University in:

Postprints der Universität Potsdam

Humanwissenschaftliche Reihe ; 527

ISSN 1866-8364

http://nbn-resolving.de/urn:nbn:de:kobv:517-opus4-414898

DOI https://doi.org/10.25932/publishup-41489 



\title{
Preposition copying and pruning in present-day English
}

\author{
ANDREW RADFORD \\ University of Essex \\ CLAUDIA FELSER \\ University of Potsdam \\ and \\ OLIVER BOXELL \\ University of Potsdam
}

(Received 1 August 2011; revised 15 February 2012)

\begin{abstract}
This article investigates the nature of preposition copying and preposition pruning structures in present-day English. We begin by illustrating the two phenomena and consider how they might be accounted for in syntactic terms, and go on to explore the possibility that preposition copying and pruning arise for processing reasons. We then report on two acceptability judgement experiments examining the extent to which native speakers of English are sensitive to these types of 'error' in language comprehension. Our results indicate that preposition copying creates redundancy rather than ungrammaticality, whereas preposition pruning creates processing problems for comprehenders that may render it unacceptable in timed (but not necessarily in untimed) judgement tasks. Our findings furthermore illustrate the usefulness of combining corpus studies and experimentally elicited data for gaining a clearer picture of usage and acceptability, and the potential benefits of examining syntactic phenomena from both a theoretical and a processing perspective.
\end{abstract}

\section{Introduction}

Radford (2010a, b) reports on wh-clauses occurring in a corpus of live, unscripted broadcasts on British radio and TV stations. ${ }^{1}$ These included instances of PREPOSITION COPYING in wh-clauses like those bracketed in (1) below, in which one (bold-printed) occurrence of the highlighted preposition appears at the beginning of the (bracketed) wh-clause, and another (italicised) occurrence appears at the end:

(1) (a) Spurs have got four strikers [from which to choose from] (Mark Lawrenson, BBC Radio 5)

\footnotetext{
1 The data were taken from live unscripted broadcasts in order to avoid possible prescriptive influences from copy-editors. The main sources were popular sports broadcasts from BBC Radio 5 Live, BBC Radio 5 Sports Extra, BBC World Service, Talk Sport Radio, BBC TV, ITV and Sky TV. Programmes recorded included sports discussion forums (like Radio 5's 'Monday Night Club' and Sky's 'Sunday Supplement'), sports phone-ins (like Radio 5's 'World Football Phone-In' and Sky's 'You're on Sky Sports') and live sports commentaries. The data were digitally recorded (and transcribed) by Andrew Radford from May 2010 to May 2011. The overall size of the corpus was around 400 hours and 2.5 million words. The examples in (1), (2) and the data in table 1 are derived from this corpus.
} 
Table 1. Raw frequency of preposition copying/pruning in different types of wh-clause

\begin{tabular}{lcc}
\hline \hline Type of wh-clause & Preposition copying & Preposition pruning \\
\hline Null-operator restrictive relative clause & 0 & 50 \\
Wh-operator restrictive relative clause & 13 & 7 \\
Wh-operator free relative clause & 2 & 15 \\
Wh-operator appositive relative clause & 6 & 9 \\
Wh-operator interrogative clause & 2 & 1 \\
Total & 23 & 82 \\
\hline \hline
\end{tabular}

(b) Israeli soldiers fired an anti-tank missile and hit a police post [in which the Palestinian policeman who was killed had been in] (News reporter, BBC Radio 5)

(c) Tiger Woods, [about whom this Masters seems to be all about], is due to tee off shortly (Ian Carter, BBC Radio 5)

(d) They're all striving for the health of the European Tour, of which they're all members of (Colin Montgomerie, BBC Radio 5)

(e) It's quite clear [on which side of the Blair-Brown divide that Alistair Campbell comes down on] (Political correspondent, BBC Radio 5)

At the same time, the corpus also contained instances of Preposition Pruning structures like those bracketed in (2) below in which a wh-constituent apparently functioning as a prepositional object occurs without the relevant preposition being overtly spelled out within the clause in question (the convention adopted here being to signal the 'missing' preposition by strikethrough): ${ }^{2}$

(2) (a) That's the situation [that Obama and, to some extent, the party find themselves in] (Reporter, BBC Radio 5)

(b) One of the things [we want to make sure $\theta f$ ] is that people do change their behaviour (Government spokesman, BBC Radio 5)

(c) It's something [we are working $ө n$ with our suppliers] (Businessman, BBC Radio 5)

(d) It's a fun exercise, rather than something [that Messrs Miller and Flower will have any input (Jonathan Agnew, BBC Radio 5 Sports Extra)

(e) This is a matter [for people to make their minds up (Dave Watts, BBC Radio 5)

Table 1 summarises the raw frequency of preposition copying and pruning in various types of wh-clause in our corpus.

2 Our discussion of preposition pruning abstracts away here from clauses like those bracketed below in which a preposition can (it might seem) standardly have a null spellout:

(i) The way [he played] was imperious (cf. 'The way [in which he played] was imperious')

(ii) That's why I'm in the position [that I am in] (Mark Webber, BBC Radio 5)

Sentences like (i) arguably involve a null oblique operator, while sentences like (ii) involve ellipsis of the complement of be, and thus are parallel to:

(iii) They were surprised to find her living in the house [that she was living in] 
Table 1 shows that preposition pruning occurs almost four times as frequently as preposition copying in our corpus overall, and that nearly two-thirds of the total number of preposition pruning tokens are found in restrictive relative clauses that lack an overt wh-operator.

The key question to be addressed in this article is: 'What is the source of preposition copying, and of preposition pruning, and are the two phenomena inter-related - and if so how?' We begin by looking (in section 2 below) at whether preposition copying and preposition pruning can be characterised in syntactic terms. We then consider the two phenomena from a processing perspective in section 3, discussing how they might arise during language production. We go on to present the results of two experiments designed to obtain novel sets of judgement data in section 4, which reveal that the multiple spellout of prepositions - but not their omission - is considered highly acceptable by native speakers of English. Our overall conclusions are presented in section 5.

\section{A syntactic account}

Radford (2009: 236) sketches a syntactic analysis of preposition fronting, stranding, copying and deletion in sentences such as the following:

(3) (a) The world [in which we are living] is changing

(b) The world [which we are living in] is changing

(c) ${ }^{*}$ The world [in which we are living in] is changing

(d) *The world [which we are living] is changing

As an informal characterisation of the bracketed relatives clauses in (3), we can take (3a) to involve preposition pied-piping, (3b) preposition stranding, (3c) preposition copying, and (3d) preposition pruning: only preposition pied-piping and stranding structures are generally considered to be grammatical (as reflected by the asterisks above). Given that (as Abels 2003 has shown) preposition pied-piping is the norm crosslinguistically (preposition stranding being a relatively rare phenomenon in typological terms), Radford (2009: 236) hypothesises that 'Preposition pied-piping is obligatory in English (and universally)' but that 'languages (and language varieties) may differ with regards to which link/s of a movement chain the preposition is spelled out on.' 3 Reasoning along these lines, we might suppose that English has the following two alternative ways of spelling out pied-piped prepositions:

(4) (i) High Spellout Rule

The preposition can be given an overt spellout on the highest link of a chain.

\footnotetext{
3 As an anonymous reviewer points out, there are potential parallels between the high and low spellout of prepositions and the high and low spellout of moved wh-constituents posited in Pesetsky (2000) and Reintges, LeSourd \& Chung (2006), under which wh-movement is claimed to be universal, with wh-ex-situ languages like English showing high spellout of wh-copies, and wh-in-situ languages like Japanese showing low spellout. A further potential parallel highlighted by the same reviewer is with the claim made by Bošković (2001) that Serbo-Croatian 2nd position clitics move in syntax, and that the PF component later spells out whichever copy of the moved clitic satisfies phonological requirements on clitic placement.
} 
(ii) Low Spellout Rule

The preposition can be given an overt spellout on the lowest link of a chain.

It will then follow that obligatory preposition pied-piping in the bracketed clauses in (3) will yield the structure shown in simplified form below (if relative clauses involve wh-movement to spec-CP, and if movement involves copying - as in Chomsky 1981, 1995): ${ }^{4}$

(5) [CP in which [C $\varnothing]$ we are living in which]

Preposition fronting structures like (3a) result when the High Spellout Rule (4i) is applied to the structure in (5); preposition stranding structures like (3b) when the Low Spellout Rule (4ii) is applied; preposition copying structures like (3c) when both rules are applied, and preposition deletion structures like (3d) when neither spellout rule is applied..$^{5}$ How the two spellout rules in (4) apply is governed by principles of UG. One such is the following (which dates back in spirit to work in the 1960s on the recoverability of deletion):

(6) Recoverability Condition

Lexical items can only have a null spellout if their content is recoverable (e.g. from an antecedent).

It follows from (6) that not giving either copy of a pied-piped preposition an overt spellout (i.e. not applying either spellout rule in 4) will result in ungrammaticality. A second principle of UG which has been claimed (e.g. by Nunes 1995, 2004 and Chomsky 2008) to constrain spellout in movement chains is the following:

\section{(7) Economy Condition on Spellout}

Spell out the minimal links in a chain required to ensure convergence.

What (7) means in more concrete terms is that (for economy reasons) only one link in a movement chain will normally be spelled out overtly (unless some independent constraint forces an additional link to be spelled out as well). If we suppose that there is no grammatical requirement for pied-piped prepositions to be doubly spelled out in English, this means that preposition copying will result in ungrammaticality - and indeed preposition copying structures are treated as ungrammatical by Pullum (2007) and Staum \& Sag (2008). The ungrammaticality arises because the Economy Condition (7) rules out applying both spellout rules in (4).

\footnotetext{
4 A technical complication set aside here (to simplify exposition) is whether the fronted wh-constituent moves to the edge of the verb phrase before moving to the edge of CP, as in Chomsky (1986) and much subsequent work.

5 Commenting on internet examples of preposition copying structures such as (i) below:
}

(i) A bit-part role is something [to which Traore grew accustomed to] during his time at Liverpool...

Pullum (2007) contends that a copying structure like (i) cannot result from movement of a copy of PP, since this would be expected to result in to which Traore grew accustomed to which. However, if we suppose that a copy of a wh-operator can only be spelled out in an operator position (viz. Spec-CP), his objection is without force, since spelling out a copy of which after to in (i) would yield an illicit wh-chain with two operators and no variable. 
The overall conclusion which our discussion here leads us to is that preposition fronting and preposition stranding are grammatical in English, but preposition copying and preposition deletion are ungrammatical (by virtue of violating UG constraints on economy of spellout and recoverability of deletion).

However, an important complication is that the judgements of native speakers can be affected by explicit prescriptive rules inculcated during the formative years of their education, which can lead to their judgements being distorted by a grammatical virus (as argued by Sobin 1997). One such prescriptive rule can be paraphrased informally as follows:

(8) A prepositional object must be immediately preceded by its governing preposition.

Native speakers operating with a prescriptive grammar (p-grammar) which incorporates the prescriptive rule (8) would be expected to show a rather different pattern of grammaticality or acceptability judgement in relation to sentences like (3) from speakers operating with a descriptive grammar (d-grammar) which lacks this rule. More specifically, speakers with a p-grammar would be expected to reject preposition stranding and preposition pruning structures (because in neither of these cases is the prepositional object immediately preceded by an overt copy of its governing preposition), but to accept preposition fronting structures (because these result in a structure in which a prepositional object is immediately preceded by an overt copy of its governing preposition). They would also be expected to reject preposition copying structures, because although these are compatible with the prescriptive rule in (8), they would be ruled out by the economy constraint on spellout in (7). Thus speakers operating with $\mathrm{d}$ - and $\mathrm{p}$-grammars would both be expected to accept preposition fronting and reject preposition pruning and copying, but would differ in that speakers with dgrammars would accept (and speakers with p-grammars would reject) preposition stranding structures.

\section{Processing accounts}

Our characterisation of preposition copying and preposition pruning structures in terms of the misapplication of the two spellout rules in (4), resulting in violations of conditions (6) or (7), leaves open the question of how such utterances might arise. As the tokens in our corpus were from live broadcasts and so produced in situations of high processing pressure, with limited opportunity for speakers to plan their utterances very far ahead, it is possible that the two phenomena under investigation are speech production errors facilitated by a relatively high processing load.

On the assumption that preposition pied-piping and preposition stranding have distinct grammatical representations (or that the grammar of English requires spellout rule (4i) and spellout rule (4ii) to apply mutually exclusively), both preposition copying and pruning could potentially be characterised as syntactic blending errors. That is, they might be speech production errors resulting from the competition or amalgamation of two alternative structural representations during the sentence planning stage. From 
a left-to-right processing perspective, preposition copying errors in sentences like (3c) above might then start out as preposition pied-piping structures such as (3a), but with the grammatical representation underlying them subsequently being overridden by the representation underlying preposition stranding structures like (3b). According to Coppock (2010: 48), such syntactic blends arise when 'multiple formulations of the same message are developed in the same memory buffer', with two alternative representations interacting and competing during grammatical structure building.

Preposition pruning structures like (3d), on the other hand, might arise if preposition stranding representations compete with pied-piping representations during sentence production. That is, the speaker initially activates a stranding representation which is subsequently overridden by the alternative pied-piping one, again creating a syntactic blending error - albeit one which results in the absence of any structural slot for spelling out the preposition. If this is correct, then the fact that preposition pied-piping is much rarer in spoken compared to written English (Gries 2002) may explain why in our corpus we found many more examples of preposition pruning than instances of preposition copying, which involves pied-piping (compare table 1). Note that on the hypothesis that both preposition copying and preposition pruning are speech production errors, we would expect readers or listeners to show sensitivity to such errors and to judge both preposition copying and preposition pruning tokens as unacceptable.

An alternative possibility is that preposition copying and preposition pruning might result from spellout errors during wh-dependency formation. On this view, the two phenomena under investigation would merely involve the redundant insertion of phonological forms into, or their omission from, otherwise well-formed underlying sentence representations, rather than grammatical planning errors. Processing whdependencies in wh-fronting languages like English requires the temporary storage of the fronted wh-expression in working memory and its subsequent retrieval from memory at a corresponding 'gap' position further downstream (compare e.g. Gibson 1998). Processing resource limitations might occasionally prevent speakers from remembering the fronted wh-expression's exact phonetic form at the point at which it needs to be mentally reactivated, i.e. at the foot of the chain. A similar memory decay could also occur, in principle, during comprehension. In this sense, preposition copying and/or pruning may not be modality specific.

Either way, if during language comprehension, listeners or readers are able to activate the 'correct' underlying grammatical and semantic representations despite redundant or missing prepositions, then preposition copying and/or pruning structures might actually be judged acceptable.

Utterances involving preposition copying would then come about if a speaker who starts producing a pied-piping structure, when trying to reconstruct the missing prepositional phrase at the point of the gap, no longer remembers already having spelled out the preposition and thus spells it out again, as indicated in (9). ${ }^{6}$

\footnotetext{
${ }^{6}$ This hypothesis is supported by examples like the following, where it seems clear (from the underlined conjunct) that the speaker forgot that he had pied-piped of along with which:
} 
(9) the world [CP [PP [P in] [D which]] we are living [PP [P in] [D

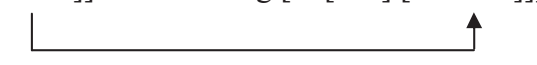

On the analysis sketched in (9), preposition copying only involves the insertion of redundant phonetic material into otherwise grammatical structural representations. Note that in copying just the preposition (rather than the full wh-phrase), speakers avoid generating strings that violate Rizzi's (1990) wh-criterion, as spelling out a copy of which after in in (9) would yield an illicit wh-chain with two operators and no variable. However, spelling out a preposition again at the foot of a wh-chain does not seem to affect a sentence's meaning or render it uninterpretable.

A corresponding analysis of preposition pruning would require us to assume that (overt or covert) preposition pied-piping is obligatory in English, a possibility suggested in section 2 above. On this view, preposition pruning will result if a speaker who intends to produce a preposition stranding structure later mistakenly thinks that the preposition was already spelled out on the left clausal periphery; see (10) below for illustration.

(10) the world [CР [PP [P in] [D which]] we are living [PP [P in] [D which]]]

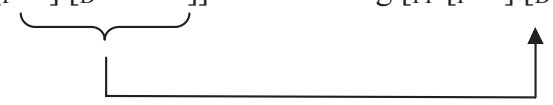

Given that in sentence production, the message to be conveyed is perfectly clear to the speaker, a failure to spell out a required preposition (or prepositional phrase) altogether may go completely unnoticed by the speaker himself or herself. Unlike preposition copying, preposition pruning may, however, create comprehension problems for listeners or readers. To gain a clearer picture of the degree to which preposition copying and pruning are considered unacceptable, we carried out two judgement experiments under controlled conditions. ${ }^{7}$

If both preposition copying and pruning sentences have recoverable, underlying globally grammatical representations and are fully interpretable and instead involve problems with wh-dependency formation or spellout, then informants might judge preposition copying sentences like (3c) above and preposition pruning sentences like (3d) above to be acceptable. However, we might expect to see an asymmetry between preposition copying and pruning reflecting the fact that in the case of preposition copying, the additional spellout of a pied-piped preposition at the foot of the wh-chain merely creates redundancy (because the preposition is spelled out in two different places), whereas sentences that involve preposition pruning might be comparatively difficult to process and comprehend (because a preposition playing an important role in the syntax and semantics of the sentence is 'missing'). As noted in section 2 above, informants' judgements may also be influenced by the prescriptive rule in (8), which

(i) MLS when it started in 1996 saw the NASL as a failure of which they didn't want to be reminded of or compared to (Sean Wheelock, BBC Radio 5)

7 The potential advantages of controlled judgement experiments are discussed e.g. by Cowart (1997), Myers (2008) and Schütze (1996). 
disfavours preposition stranding - a possibility we sought to minimise by using a timed judgement task in Experiment 2.

\section{Acceptability judgements}

In section 3 above we hypothesised that rather than being random slips of the tongue, the fairly large number of preposition copying and pruning tokens we found in our spoken language corpus may have underlying grammatical representations. We suggested more specifically that they might result either from structural competition during sentence planning or from copying phonetic material during wh-dependency formation. As corpus data alone cannot shed any further light on this issue, we went on to carry out a set of acceptability judgement tasks. In the light of the above discussion, the following predictions can be made:

- If utterances involving preposition copying or preposition pruning are production errors which cannot be mapped onto globally grammatical representations, we expect them to elicit markedly lower acceptability ratings than corresponding grammatical sentences.

- If, on the other hand, preposition copying and preposition pruning have underlying grammatical representations and result from the failure to remember the correct phonetic form of a fronted wh-expression when coming across a wh-gap, which may also happen during comprehension, we might expect both of them to elicit fairly high acceptability ratings.

- Any potential influence of prescriptive norms (such as the prohibition against preposition stranding in (8) above) on participants' judgements should be reflected more strongly in an untimed than in a timed judgement task.

- Furthermore, we might find linearisation options that facilitate the mental computation of wh-dependencies (by spelling out the preposition at least once) to be preferred over those which make comprehension difficult (as might be argued for preposition pruning), an effect that should be stronger in a timed compared to an untimed judgement task.

To test these predictions, we carried out both an untimed acceptability rating task (Experiment 1) and a corresponding timed or 'speeded' acceptability judgement task (Experiment 2), the details of which are described below.

\subsection{Experiment 1: Offline acceptability ratings}

The purpose of our first experiment was to obtain a novel set of graded acceptability judgement data from English native speakers, to examine the extent to which ungrammatical sentences involving either preposition copying or preposition pruning are felt to be unacceptable, and how their acceptability scores compare with those of corresponding grammatical sentences. 


\subsubsection{Method}

4.1.1.1 Participants. Twenty native speakers of English (15 female) aged between 19 and 24 (mean: 21.8) and with no known language or reading impairments participated in a paper-and-pencil acceptability rating task. They were all recruited from the University of Essex staff and student communities and were offered a small fee to compensate them for their time and effort.

4.1.1.2 Materials. The experiment had a $2 \times 2$ design with the factors Stranding (yes/no) and Pied-Piping (yes/no), yielding four experimental conditions as shown in (11a-d) below.

(11) (a) Preposition copying (+Stranding, +Pied-Piping) Games developers have created a world in which people truly want to lose themselves in.

(b) Preposition Pied-Piping (-Stranding, +Pied-Piping)

Games developers have created a world in which people truly want to lose themselves.

(c) Preposition stranding (+Stranding, -Pied-Piping)

Games developers have created a world which people truly want to lose themselves in.

(d) Preposition pruning (-Stranding, -Pied-Piping)

Games developers have created a world which people truly want to lose themselves.

Our materials included 24 such sentence quadruplets all containing restrictive relative clauses, and with their form and content modelled after some representative or 'typical' examples from our production corpus (Radford \& Felser 2011). The relative clauses all modified an inanimate noun phrase and always contained the wh-pronoun which combined with one of the prepositions in, from, about, for, of, to or on. The four conditions $(11 \mathrm{a}-\mathrm{d})$ were created by manipulating whether and where in a given sentence copies of the preposition were spelled out.

Half of the experimental items were ungrammatical as they contained either a second copy of a pied-piped preposition, as in (11a), or lacked a required preposition altogether, as in (11d). Conditions (11b) and (11c) served as the grammatical controls for the preposition copying (11a) and preposition pruning items (11d), respectively. Grammatical sentences of the type shown in (11b) involved preposition pied-piping, whereas sentences of the type shown in (11c) involved preposition stranding.

All experimental sentences were between 13 and 15 words in length and the end of each sentence was indicated by a full stop that followed the last word. The hypothesised ill-formedness of conditions (11a) and (11d) only became detectable at the final word. Note that neither the presence or absence of a preposition at the start of the relative clause nor its presence or absence in sentence-final position was confounded with grammaticality here. This is important to prevent participants from developing any potential response strategies based on where in a given sentence the preposition (first) appears.

The experimental items were distributed across four presentation lists using a Latin Square design, to ensure that each participant only saw a single version of each experimental item but an equal number of items per experimental condition. 


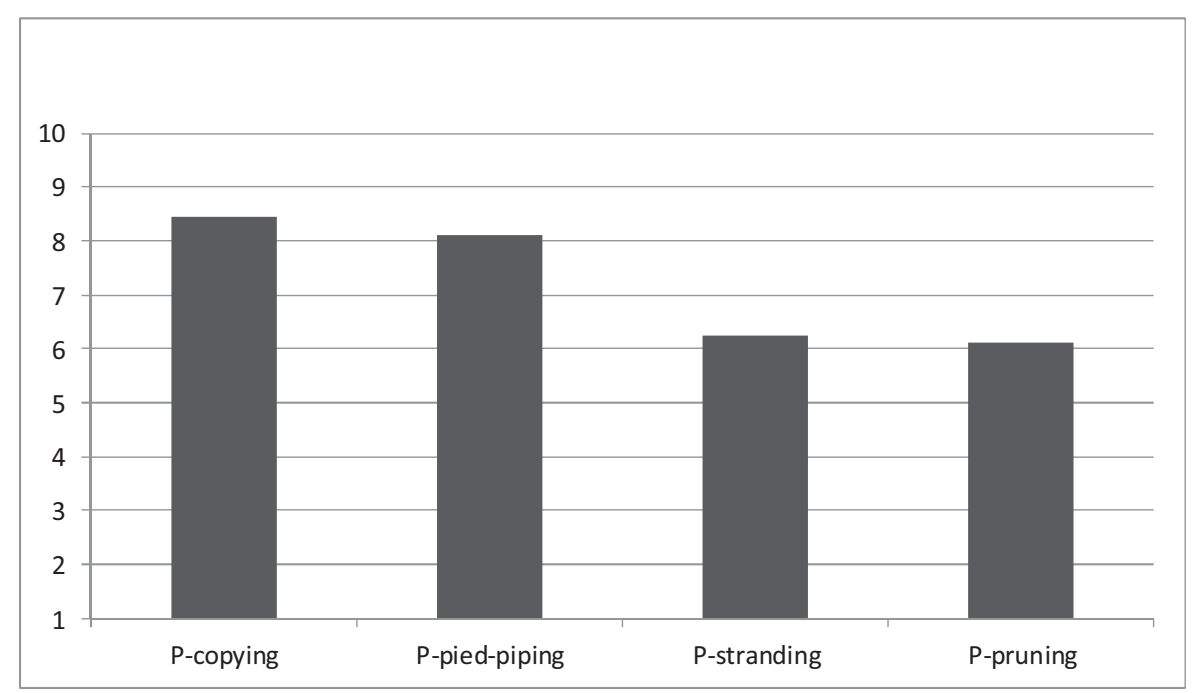

Figure 1. Average acceptability ratings (out of a maximum of 10) for the four experimental conditions, Experiment 1

A complete list of our experimental sentences is provided in the Appendix. The experimental sentences were mixed with 48 filler sentences (half grammatical and half ungrammatical), yielding 72 stimulus sentences per list in total, whose presentation order was then pseudo-randomised. The set of filler items included 36 sentences with different syntactic structures, as well as six grammatical and six ungrammatical 'pseudo-fillers' that contained relative clauses of different types (e.g. The woman with whom Terry once had a romantic affair has left the country).

4.1.1.3 Procedure. Each participant was tested individually in a quiet room. Participants were asked to read each sentence carefully and then to judge, on an ascending scale of 1-10, how well-formed and meaningful they considered them to be.

\subsubsection{Results}

Figure 1 provides an overview of participants' mean rating scores for the four experimental conditions. As figure 1 shows, all experimental conditions received average ratings of 6 or above. Sentences in which the preposition was spelled out immediately adjacent to which such as $(11 \mathrm{a}, \mathrm{b})$ generally received higher scores than those that did not involve pied-piping of the preposition (11c, d). Surprisingly, it was the (putatively ungrammatical) preposition copying condition (11a) that received the numerically highest rating.

A repeated-measures analysis of variance (ANOVA) was carried out on participants' judgement scores with the factors Stranding (yes/no) and Pied-Piping (yes/no). This yielded significant main effects of Pied-Piping $\left(\mathrm{F}_{1}(1,18)=14.532, p<.001\right.$; $\left.\mathrm{F}_{2}(1,22)=12.322, p<.001\right)$ and of Stranding in the item analysis $\left(\mathrm{F}_{1}(1,18)=\right.$ $\left.1.664, p>.05 ; \mathrm{F}_{2}(1,22)=13.001, p<.001\right)$, as well as a significant interaction 
Table 2. Average acceptability ratings (SDs in parentheses) and between-condition differences, Experiment 1

\begin{tabular}{|c|c|c|c|}
\hline & Pied-piping & & \\
\hline \multirow{3}{*}{$\begin{array}{l}\text { Stranding } \\
+\end{array}$} & + & - & difference \\
\hline & Preposition copying & P-stranding & \\
\hline & $8.43(0.26)$ & $6.25(0.86)$ & $2.18^{*}$ \\
\hline \multirow[t]{2}{*}{-} & P-pied-piping & Preposition pruning & \\
\hline & $8.1(0.48)$ & $6.12(0.92)$ & $1.98^{*}$ \\
\hline difference & 0.33 & 0.13 & \\
\hline
\end{tabular}

* Significant at $p<.001$

between these two factors $\left(\mathrm{F}_{1}(1,18)=11.132, p<.001 ; \mathrm{F}_{2}(1,22)=10.665, p<.001\right)$. To further explore the source of this interaction, planned pairwise comparisons were then carried out. These showed significant differences between preposition copying and stranding $\left(t_{1}(19)=3.325, p<.001 ; t_{2}(23)=3.452, p<.001\right)$ and between preposition pied-piping and pruning $\left(t_{1}(19)=3.216, p<.001 ; t_{2}(23)=3.128, p<\right.$ $.001)$. The relatively smaller differences between preposition copying and pied-piping, and between preposition stranding and pruning, were not statistically significant. The results from Experiment 1 are summarised in table 2.

Additional comparisons between the preposition copying and pruning conditions (with the significance level Bonferroni-corrected to .008) confirmed that the difference between these was significant as well $\left(t_{1}(19)=3.218, p<.001 ; t_{2}(23)=3.884\right.$, $p<.001)$, as was the difference between pied-piping and stranding $\left(t_{1}(19)=3.217\right.$, $\left.p<.001 ; t_{2}(23)=3.302, p<.001\right)$.

\subsubsection{Summary}

The results from Experiment 1 show that putatively ungrammatical sentences like (11a) or (11d) actually elicited similar acceptability ratings to their grammatical controls, (11b) and (11c). We also found that sentences which contained a pied-piped preposition such as $(11 \mathrm{a}, \mathrm{b})$ received significantly higher ratings than those which did not $(11 \mathrm{c}$, d). The relatively low rating elicited by (descriptively grammatical, but prescriptively ungrammatical) preposition stranding sentences could be taken to suggest either (i) that participants' rating scores were partly based on prescriptive norms (cf. rule (8) above) or (ii) that preposition pied-piping generally facilitates the processing of wh-clauses or perhaps both.

\subsection{Experiment 2: Timed acceptability judgements}

Timed judgement tasks with controlled stimulus presentation are thought to give participants comparatively little time to reflect consciously on their responses, thus minimising the possibility of their judgements being influenced by metalinguistic knowledge, prescriptive norms or stylistic rules (compare e.g. Schütze 1996). We used a speeded acceptability judgement task in which the stimulus sentences are presented 
one word at a time in quick succession, a method that has been claimed to be similar to real-time auditory processing in some respects and which can give us an indication of relative processing difficulty (Blackwell, Bates \& Fisher 1996). In this kind of task, increased processing difficulty is assumed to be reflected in lower response accuracy, longer response latencies, or both.

\subsubsection{Method}

4.2.1.1 Participants. A different group of twenty native speakers of British English (17 female) aged between 19 and 26 (mean: 20.7), recruited from the same participant pool as those who took part in Experiment 1, participated in a speeded judgement task. All participants had normal or corrected to normal vision and no known language or reading impairments. They also received a small fee to compensate them for their time and effort.

\subsubsection{Materials. The materials were the same as those used in Experiment 1.}

4.2.1.3 Procedure. Participants were tested individually in a quiet room. Stimulus presentation and the recording of participant responses were controlled by the experimental software package DMDX (Forster \& Forster 2003). An experimental trial began with a fixation cross shown in the centre of a 17-inch computer screen for $500 \mathrm{~ms}$ to signal that a stimulus sentence was about to appear and to focus participants' attention. The stimulus sentences were then presented in the middle of the screen one word at a time at a rate of $250 \mathrm{~ms}$ per word. All stimuli were shown in white letters on a black background, with a font size of 30 in Arial. Immediately after reading the final word, participants were required to judge as quickly and as accurately as possible whether or not a given string was well-formed and meaningful in English, by pressing a corresponding 'yes' or 'no' button on a PC game pad. Each experimental session started with three practice items, to allow participants to familiarise themselves with the task. Participants were offered a break approximately every twenty items, and an experimental session lasted no longer than approximately 40 minutes.

\subsubsection{Results}

4.2.2.1 Acceptability judgements. Figure 2 presents an overview of participants' mean proportions of 'yes' responses across the four experimental conditions. While the preposition copying, pied-piping and stranding conditions all elicited a clear majority of positive judgements, sentences involving preposition pruning were overwhelmingly rejected. Similar to what we saw in Experiment 1, preposition copying elicited the highest proportion of positive judgements numerically, with a mere 10 per cent of the trials in this condition being rejected.

A repeated-measures ANOVA on participants' 'yes' responses with the factors Stranding (yes/no) and Pied-Piping (yes/no) showed significant main effects of Stranding $\left(\mathrm{F}_{1}(1,18)=48.837, p<.001 ; \mathrm{F}_{2}(1,22)=55.432, p<.001\right)$ and of Pied-Piping $\left(\mathrm{F}_{1}(1,18)=116.935, p<.001 ; \mathrm{F}_{2}(1,22)=54.326, p<.001\right)$ as well as a significant two-way interaction $\left(\mathrm{F}_{1}(1,18)=80.252, p<.001 ; \mathrm{F}_{2}(1,22)=63.212\right.$, $p<.001)$. Subsequent planned pairwise comparisons revealed significant differences 
Table 3. Mean percentages of 'yes' responses (SDs in parentheses) and between-condition differences, Experiment 2

\begin{tabular}{|c|c|c|c|}
\hline & Pied-piping & & \\
\hline \multirow{3}{*}{$\begin{array}{l}\text { Stranding } \\
+\end{array}$} & + & - & difference \\
\hline & Preposition copying & P-stranding & \\
\hline & $90(14.6)$ & $76.6(25.4)$ & 13.4 \\
\hline \multirow[t]{2}{*}{-} & P-pied-piping & Preposition pruning & \\
\hline & $81.6(16.5)$ & $25.1(10.7)$ & $56.5^{*}$ \\
\hline difference & 8.4 & $51.5^{*}$ & \\
\hline
\end{tabular}

* Significant at $p<.001$

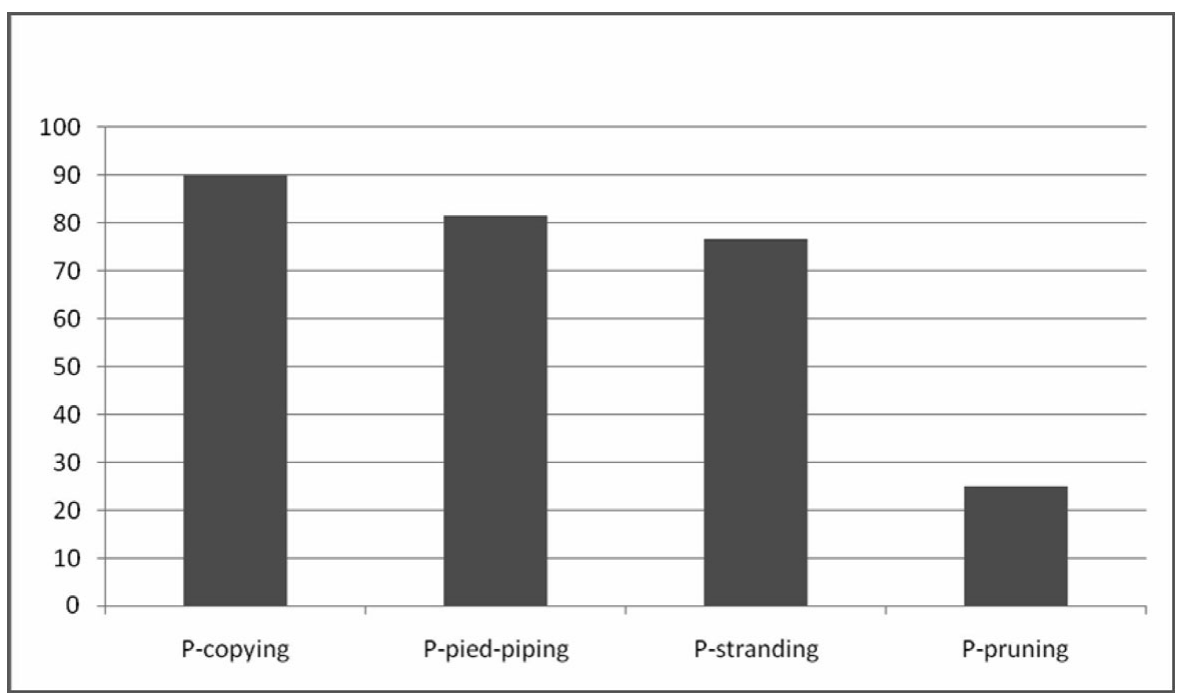

Figure 2. Mean percentages of 'yes' judgements for the four experimental conditions, Experiment 2

between preposition pied-piping and pruning $\left(t_{1}(19)=8.891, p<.001 ; t_{2}(23)=\right.$ $7.104, p<.001)$ and between preposition stranding and pruning $\left(t_{1}(18)=8.453\right.$, $\left.p<.001 ; t_{2}(22)=8.120, p<.001\right)$. No significant differences were found between preposition copying and pied-piping, or between preposition copying and stranding. The main descriptive and statistical results are summarised in table 3 below.

The differences between the preposition copying and pruning conditions also proved significant $\left(t_{1}(19)=10.784, p<.001 ; t_{2}(23)=9.899, p<.001\right.$, with $\alpha$-level corrected to .008), confirming that participants' judgements of the preposition pruning condition differed reliably from their judgements of all other experimental conditions. The difference between preposition pied-piping and stranding was not significant.

4.2.2.2 Response times. Figure 3 provides an overview of participants' mean response times across the four experimental conditions for 'yes' and 'no' responses 


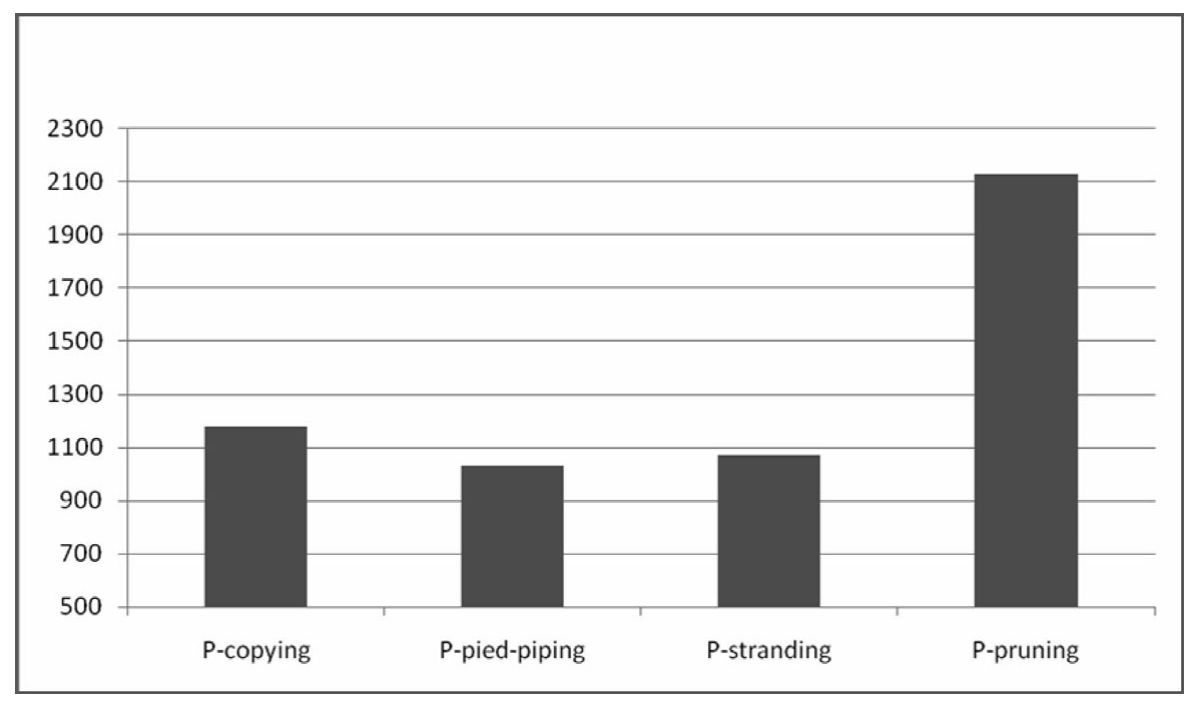

Figure 3. Mean response times (in milliseconds) per condition, Experiment 2

aggregated. ${ }^{8}$ It shows that it took participants about twice as long, on average, to judge sentences that involved preposition pruning as it took them to judge items from the three other experimental conditions.

A repeated-measures ANOVA showed significant main effects of Stranding $\left(\mathrm{F}_{1}(1\right.$, $\left.18)=24.031, p<.001 ; F_{2}(1,22)=21.113, p<.001\right)$ and of Pied-Piping $\left(F_{1}(1\right.$, $\left.18)=15.935, p<.001 ; \mathrm{F}_{2}(1,22)=19.332, p<.001\right)$, and the interaction between these was also significant $\left(\mathrm{F}_{1}(1,18)=25.035, p<.001 ; \mathrm{F}_{2}(1,22)=20.445, p<\right.$ $.001)$. Planned pairwise comparisons revealed significant differences for preposition pied-piping vs pruning $\left(t_{1}(19)=5.192, p<.001 ; t_{2}(23)=4.621, p<.001\right)$ and for preposition stranding vs. pruning $\left(t_{1}(18)=6.158, p<.001 ; t_{2}(22)=5.040, p<.001\right)$, but not for preposition copying vs. pied-piping, or preposition copying vs. stranding (see table 4 for a results summary).

Preposition copying also differed significantly from pruning $\left(t_{1}(19)=4.332, p<\right.$ $.001 ; t_{2}(23)=4.871, p<.001$, with $\alpha$-level corrected to .008), whereas participants' response times to pied-piping and stranding did not differ statistically.

\subsubsection{Summary}

The results from our timed acceptability judgement task show that preposition copying, pied-piping and stranding patterned together in that they elicited equally

\footnotetext{
${ }^{8}$ An anonymous reviewer asks why 'Response times in figure $3 \ldots$ are longer than most response times one sees in the literature'. The answer is that our stimulus sentences were longer than those used in most other comparable experiments we are aware of, so participants would be expected to take some time over their decision, especially since they had been instructed to aim for accuracy as well as speed. In a series of similar experiments using the exact same procedure (Sato 2007), we measured an average response time of $750 \mathrm{~ms}$ for simple three-word sentences, of $850 \mathrm{~ms}$ for four-word sentences and of around $1200 \mathrm{~ms}$ for longer sentences (which were, however, shorter than the present stimulus materials), so the RTs we measured in the current experiment do not strike us as excessively long.
} 
Table 4. Mean response latencies (in milliseconds, SDs in parentheses) and between-condition differences, Experiment 2

\begin{tabular}{|c|c|c|c|}
\hline \multirow{4}{*}{$\begin{array}{l}\text { Stranding } \\
+\end{array}$} & \multicolumn{3}{|l|}{ Pied-piping } \\
\hline & + & - & difference \\
\hline & Preposition copying & P-stranding & \\
\hline & $1179(133.4)$ & $1073.4(334.2)$ & 105.6 \\
\hline - & P-pied-piping & Preposition pruning & \\
\hline & $1030.2(270.4)$ & $2130(410.6)$ & $-1099.8^{*}$ \\
\hline difference & 148.8 & $-1056.6^{*}$ & \\
\hline
\end{tabular}

* Significant at $p<.001$

high proportions of positive acceptability judgements statistically, as well as similar response latencies. The preposition pruning condition differed significantly from all others in that it elicited a majority of negative judgements and also took considerably longer to respond to.

\section{Discussion}

Our main findings can be summarised as follows:

- Although prescriptively ungrammatical, neither preposition copying nor preposition pruning sentences were judged to be as unacceptable as downright ungrammatical or anomalous filler items in our untimed judgement task (Experiment 1).

- Preposition copying was rated as highly as preposition pied-piping in Experiment 1, and was also overwhelmingly accepted in Experiment 2, statistically on a par with both pied-piping and stranding.

- Whilst preposition stranding and preposition pruning both received equally high scores (of around 6/10) in Experiment 1, preposition pruning was judged as acceptable significantly less often $(25.1 \%)$ than preposition stranding $(76.6 \%)$ in Experiment 2.

- Preposition pruning was the only stimulus type to be reliably rejected in Experiment 2, and also took participants significantly longer to judge than the three other stimulus types.

In the following, we will consider how these findings might be accounted for.

\subsection{Acceptability differences}

Our most striking finding is that putatively ungrammatical sentences involving preposition copying were consistently judged as acceptable by our participants and even received the highest acceptability ratings numerically. Together with our earlier observation that preposition copying also occurs in language production, this raises the question of what empirical basis there is for any claims to the effect that preposition copying is not licensed by the grammar of present-day English. The difference between grammaticality and acceptability is, of course, a difficult issue, and it is conceivable 
that what we are dealing with here is a case of 'acceptable ungrammaticality' in the sense of Langendoen \& Bever (1973). ${ }^{9}$

Nykiel (2010), for example, argues that preposition copying may be acceptable because it satisfies two processing constraints at the same time: that of minimising the distance between a verb and a preposition it selects for, which favours preposition stranding, and that of maximising the fronted wh-phrase's accessibility, which favours preposition pied-piping. ${ }^{10}$ Purely processing-based explanations of preposition copying are called into question, however, by our observation that the hypothesised processing benefits of pied-piping and stranding were not found to be additive in Experiment 2; that is, our preposition copying stimuli were not processed any faster, or judged any better statistically, than either preposition pied-piping or stranding ones. Moreover, sentence production experiments have shown that speakers, when faced with a choice between different structural or linearisation options, do not necessarily choose options that facilitate comprehension (Arnold, Wasow, Asudeh \& Alrenga 2004). It is thus unlikely that the preposition copying tokens in our corpus were produced so as to make the fronted wh-constituent more accessible for comprehenders.

From the point of view of the copy theory of movement, it is possible to analyse preposition copying as involving (phonetic or orthographic) redundancy rather than deviant structural representations. ${ }^{11}$ This would account for our finding that copying was considered highly acceptable even in the untimed judgement task in Experiment 1. After all, copying or multiple spellout phenomena are attested in many other languages (compare Barbiers, Koeneman \& Lekakou 2008; Cheng 2007; Felser 2004; Nunes 2004; Camacho 2002, among many others), suggesting that the multiple realisation of chain links is an option allowed for by Universal Grammar. Indeed, it would appear that preposition copying is grammaticalised in some languages - e.g. it is found in Berber structures like that below (from Alami in prep.):

(12) $\boldsymbol{i}$ mit ad mi yfa hassan tabrat?

To who that to gave Hassan letter

'To whom was it that Hassan give the letter?'

Such sentences involve wh-fronting of the bold-printed PP $i$ mit 'to whom', but with a second (italicised) copy of the preposition $i$ 'to' (in the guise of its augmented form

${ }^{9}$ Langendoen \& Bever observed that no formal grammar can distinguish between the relative acceptability of a not unhappy person and the unacceptable a not sad person. Examples of this kind seem to support a distinction between competence and performance grammars (Langendoen 1979). The term 'acceptable ungrammaticality' has since been used by others, such as Duffield, Matsuo \& Roberts (2007), for structures assumed to be ungrammatical, but judged to be acceptable, or failing to trigger ungrammaticality effects.

${ }^{10}$ Morphologically complex or more informative wh-phrases have been argued to be more accessible antecedents than bare wh-pronouns (Hofmeister, Jaeger, Sag, Arnon \& Snider 2007).

11 Models of language production usually distinguish a structure-building stage from a stage during which phonolexical material is inserted into structural slots. This distinction seems to be mirrored, roughly, in Chomsky's distinction between structure-building and PF-spellout. So both from a processing and a theoretical perspective, it is possible for spellout errors to occur even if the underlying structural representation has been assembled correctly. 
$m i$ 'to') being stranded in situ in the syntax and then (according to Ouhalla 2005) encliticising to the complementiser $a d$ 'that' at PF. Preposition copying is also found in some Germanic languages or dialects, e.g. in Swiss German varieties (Glaser \& Frey 2007) and in the following example from North Saxon (Niedersächsisches Wörterbuch IV: 40, cited by Fleischer 2002: 143f.).

(13) van Vöörgeschichten kann ik wal wat van vertellen of past histories can I well something of tell

'I can very well tell something about past histories'

Other forms of doubling are also attested (see e.g. Camacho 2002; Felser 2004; Barbiers et al. 2008). The fact that doubling is grammaticalised in some language varieties suggests that it should not be treated as ungrammatical. It further suggests that the Economy Condition on Spellout in (7) may not be a principle of UG as such, but rather may be what Chomsky (2008) terms a third factor principle relating to computational efficiency and governing natural systems in general, rather than language in particular. Moreover, for the kind of sentences we are examining here, copying the preposition does not seem to affect semantic interpretation or render a sentence uninterpretable.

Preposition pruning, on the other hand, was consistently judged less favourably than preposition copying (and pied-piping). In Experiment 1, participants judged our preposition pruning stimuli on a par with preposition stranding stimuli, with their moderately high rating scores indicating that neither of the two was considered downright unacceptable. The fact that in Experiment 1, preposition copying and pied-piping both elicited significantly higher ratings than preposition stranding and pruning suggests that participants' untimed judgements might have been influenced by a prescriptive rule along the lines of (8) above, repeated here for convenience.

(8) A prepositional object must be immediately preceded by its governing preposition.

This hypothesis is further supported by our finding that in Experiment 2, preposition stranding was generally deemed acceptable whilst preposition pruning was overwhelmingly rejected - a potential task effect which will be further discussed below.

Note that from the perspective of incremental structure-building during language comprehension, the assumption that pied-piping of the preposition should be obligatory in preposition stranding and pruning structures is problematic. When coming across the start of a relative clause in a string such as the world which we. . ., listeners or readers are far more likely to construct a partial syntactic representation like (14) below, with the relative clause introduced by a bare wh-pronoun, than the one shown in (10) which involves a fronted (but silent) preposition.

(14) the world [CP $[\mathrm{D}$ which $]$ we ...

At the point of the wh-gap, where the verb's subcategorisation or selectional features make it clear that the 'missing' constituent must in fact be a prepositional phrase, 
such an initial misanalysis will result in a syntactically non-uniform (and thus, illicit) wh-chain, as illustrated in (15).

(15) *the world [CP [D which ] we are living [PP in which ]]

Even if listeners or readers then backtrack and revise their initial analysis so as to include a (covert) preposition at the left clausal periphery as in (10) above, the fact that the preposition is not spelled out at all should make any such reanalysis less than straightforward, and might give rise to further processing and comprehension difficulty. Complex inferencing may need to be used here to infer the content of the 'missing' constituent at the foot of the chain. In grammatical terms, this might be captured by a (recoverability) constraint along the lines of (6), repeated below:

(6) Recoverability Condition

Lexical items can only have a null spellout if their content is recoverable (e.g. from an antecedent).

To the extent that any syntactic reanalysis at all is required in the case of preposition stranding (as has been suggested, for example, by Hornstein \& Weinberg 1981), this should be comparatively easier given that unlike preposition pruning, stranding does not violate condition (6).

\subsection{Task effects}

The most obvious difference between the results from Experiments 1 and 2 is the fact that preposition pruning was considered no worse than preposition stranding in Experiment 1 but was predominantly rejected in Experiment 2, whilst preposition stranding was generally accepted. That the acceptability of preposition pruning should be further reduced in situations of increased processing pressure, as in the kind of word-by-word timed judgement task used in Experiment 2, is unsurprising under the processing scenario outlined above. Successfully recovering a missing preposition is bound to be more difficult under time pressure, or where processing resources are short.

Participants' judgements of preposition stranding were also affected by task differences, albeit in the opposite direction. Whilst eliciting significantly poorer acceptability ratings than either preposition copying or pied-piping in Experiment 1, preposition stranding was judged as acceptable the same proportion of times as the former two, and as significantly more acceptable than preposition pruning, in Experiment 2. This difference can be accounted for by the assumption that participants' untimed judgements were influenced by a prescriptive rule such as (8) that biased them against preposition stranding, whose influence was, however, absent or reduced in the timed version of the task that we used in Experiment 2. Our findings thus underline the usefulness of supplementing offline judgement data with data from timed or processing tasks, in order to minimise the possibility of informants' judgement being influenced by prescriptive norms that may not necessarily form part of their competence grammar.

Participants' judgements of preposition copying differed sharply from their judgements of preposition pruning in Experiment 2, where copying was accepted 
90 per cent of the time on average whereas pruning was mostly rejected. Given that a fair amount of material intervened between the fronted preposition and its copy in our experimental materials, the surprisingly high acceptance rate for copying could be taken to support an account of preposition copying in terms of a spellout error facilitated by processing resource limitations and leading to redundancy rather than deviance. Further support for this hypothesis can be gathered from the results of a reading-time experiment reported by Staum \& Sag (2008), which showed that the relative difficulty of processing preposition copying structures was affected by the amount of material intervening between the two copies of the preposition. Readers were found to be slowed down by a copied preposition only if both copies were relatively close together but not if they appeared further apart. In future research, it would be interesting to test the way sentence complexity and working memory shortages affect participants' judgement or comprehension of preposition copying more systematically.

\subsection{Production vs comprehension}

Our data show that preposition copying is not modality-specific, in that it is not restricted to language production but is also considered highly acceptable in comprehensionbased tasks. This would be expected under the assumption that preposition copying creates (phonetic or orthographic) redundancy rather than ungrammaticality, through the simultaneous application of spellout rules (4i) and (4ii). Our findings suggest that rather than reflecting grammatical planning errors during speech production, preposition copying results from redundant spellout, with underlying grammatically and semantically well-formed representations that readers or listeners are able to recover during comprehension.

There is, however, an asymmetry between our corpus data and the results from our acceptability judgement tasks showing that preposition copying occurred much less frequently than preposition pruning in our spoken corpus, whereas copying was judged as significantly more acceptable than pruning in Experiments 1 and 2. Besides noting that frequency is not an indicator of grammaticality, this asymmetry can be accounted for by processing considerations, on the assumption that preposition pruning is the most economical option from the point of view of the speaker (to whom the message to be conveyed is clear) whilst preposition copying is the more comprehension-friendly option. As remarked earlier, preposition fronting is also generally quite rare in spoken English.

As noted above, the successful comprehension of preposition pruning sentences may require syntactic reanalysis not dissimilar to the kind of reanalysis required in temporarily ambiguous 'garden path' sentences. That is, although the structural representations created in the mind of a speaker who produces preposition pruning tokens may be perfectly grammatical, the representations built during comprehension most likely are not, and violate the recoverability condition (6). Besides the high proportion of negative judgements, the significantly longer response times we observed for preposition pruning in comparison to the other three experimental conditions is 
likely to reflect the additional processing effort required for parsing and interpreting our preposition pruning stimuli.

\section{Concluding remarks}

In sections 2 and 3 above we called into question the possibility that the relatively high numbers of preposition copying and pruning tokens that we found in our spoken language corpus might merely be random slips of the tongue. Our analysis of such putative 'errors' suggests that they are not, and our experimental results fail to support any claims to the effect that preposition copying, in particular, is ungrammatical. In grammatical terms, and from the point of view of the copy theory of movement, preposition copying can be characterised as involving the simultaneous application of two alternative (high and low) spellout rules. Economy constraints that normally prevent the phonetic realisation of more than one instance of a preposition may potentially be overridden by processing factors such as the processing pressure experienced by commentators during live TV or radio broadcasts. However, our results show that the multiple spellout of prepositions was considered highly acceptable also in an untimed judgement task.

The surprisingly high acceptance rate of all three of preposition copying, pied-piping and stranding in Experiment 2 calls into question the validity of any prescriptive rules against preposition copying or stranding. Preposition pruning, on the other hand, seems predominantly a feature of (spoken) language production and elicited comparatively low acceptability ratings, indicating that pruning increases processing difficulty during language comprehension. Preposition pruning might be argued to violate a grammatical constraint to the effect that elided material must be recoverable, and may potentially prevent comprehenders from computing licit wh-chains. ${ }^{12}$

The research reported here also leads to three more general conclusions. One is the methodological point that combining corpus studies and experimentally elicited data provides a more reliable picture of usage and acceptability. A second is the theoretical point that doubling phenomena like preposition copying do not pose a problem for Chomskyan generative grammar (contrary to what has been suggested by Nykiel 2010 or Pullum 2007, for example). A third is the descriptive point that looking at syntactic phenomena from both a theoretical and a processing perspective can lead to a better understanding and characterisation of these phenomena.

\footnotetext{
12 An anonymous reviewer wonders why preposition pied-piping elicited higher acceptability ratings than preposition stranding, a difference that was statistically significant in Experiment 1 (but not in Experiment 2). The reviewer points out that either that or a null complementiser might be a more natural choice than which in the production of preposition stranding structures, suggesting that the consistent use of which in our materials could potentially account for the relatively poorer ratings of preposition stranding in our study. Even though this possibility cannot be dismissed altogether, note that any potential bias against preposition stranding in our materials cannot account for the consistently low ratings of preposition pruning structures, or for the pattern of results observed in Experiment 2, where preposition stranding was judged as acceptable as both preposition copying and pied-piping.
} 
Authors' addresses:

Department of Language and Linguistics

University of Essex

Wivenhoe Park

Colchester

Essex CO4 3SQ

$U K$

radford@essex.ac.uk

Potsdam Research Institute for Multilingualism

University of Potsdam

Campus Golm

Karl-Liebknecht-Strasse 24-25

14476 Potsdam

Germany

claudia.felser@uni-potsdam.de

boxell@uni-potsdam.de

\section{References}

Abels, Klaus. 2003. Successive cyclicity, anti-locality and adposition stranding. $\mathrm{PhD}$ dissertation, University of Connecticut.

Alami, Lahcen. In prep. Word order, agreement and resumption in the Tashelhit variety of Berber. PhD dissertation, University of Essex.

Arnold, Jennifer, Thomas Wasow, Ash Asudeh \& Peter Alrenga. 2004. Avoiding attachment ambiguities: The role of constituent ordering. Journal of Memory and Language 51, 55-70.

Barbiers, Sjef, Olaf Koeneman \& Marika Lekakou. 2008. Syntactic doubling and the structure of chains. In Charles B. Chang \& Hannah J. Haynie (eds.), Proceedings of the 26th West Coast Conference on Formal Linguistics. Somerville, MA: Cascadilla Proceedings, 77-86.

Blackwell, Arshavir, Elizabeth Bates \& Dan Fisher. 1996. The time course of grammaticality judgment. Language and Cognitive Processes 11, 337-406.

Bolinger, Dwight. 1961. Syntactic blends and other matters. Language 37, 366-81.

Bošković, Željko. 2001. On the nature of the syntax-phonology interface: Cliticization and related phenomena. Amsterdam: Elsevier.

Camacho, Juan. 2002. Wh-doubling: Implications for the syntax of wh-movement. Linguistic Inquiry 33, 157-64.

Cheng, Lisa. 2007. Verb copying in Mandarin Chinese. In Norbert Corver \& Jairo Nunes (eds.), The copy theory of movement, 151-74. Amsterdam: John Benjamins.

Chomsky, Noam. 1981. Lectures on government and binding. Dordrecht: Foris.

Chomsky, Noam. 1986. Barriers. Cambridge, MA: MIT Press.

Chomsky, Noam. 1995. The minimalist program. Cambridge, MA: MIT Press.

Chomsky, Noam. 2008. On phases. In Robert Freidin, Carlos P. Otero \& María-Luisa Zubizaretta (eds), Foundational issues in linguistic theory, 133-66. Cambridge, MA: MIT Press.

Coppock, Elizabeth. 2010. Parallel encoding of alternatives in sentence production: Evidence from syntactic blends. Language and Cognitive Processes 25, 38-49. 
Cowart, Wayne. 1997. Experimental syntax: Applying objective methods to sentence judgments. Thousand Oaks, CA: Sage.

Duffield, Nigel, Ayumi Matsuo \& Leah Roberts. 2007. Acceptable ungrammaticality in sentence matching. Second Language Research 23, 155-77.

Felser, Claudia. 2004. Wh-copying, phases, and successive cyclicity. Lingua 114, 543-74.

Fleischer, Jürg. 2002. Preposition stranding in German dialects. In Sjef Barbiers, Leonie Cornips \& Susanne van der Kleij (eds.), Syntactic microvariation. Online proceedings Workshop on Syntactic Microvariation. 30-31 August 2000, 116-51. Amsterdam: Meertens Instituut.

Forster, Ken \& Jonathan Forster. 2003. DMDX: A Windows display program with millisecond accuracy. Behavior Research Methods, Instruments \& Computers 35, 116-24.

Gibson, Edward. 1998. Syntactic complexity: Locality of syntactic dependencies. Cognition $68,1-75$.

Glaser, Elvira \& Natascha Frey. 2007. Doubling phenomena in Swiss German dialects. In Sjef Barbiers, Margreet van der Ham \& Marika Lekakou (eds.), European dialect syntax project: Papers presented at the Workshop on Syntactic Doubling. Amsterdam, March 2006. www.meertens.knaw.nl/projecten/edisyn.

Gries, Stefan. 2002. Preposition stranding in English: Predicting speakers' behaviour. In Vida Samiian (ed.), Proceedings of the Western Conference on Linguistics, vol. 12, California State University, Fresno, CA, 230-41.

Hofmeister, Philip, T. Florian Jaeger, Ivan A. Sag, Inbal Arnon \& Neal Snider. 2007. Locality and accessibility in wh-questions. In Samuel Featherston \& Wolfgang Sternefeld (eds.), Roots: Linguistics in search of its evidential base. Berlin: Mouton de Gruyter.

Hornstein, Norbert \& Amy Weinberg. 1981. Case theory and preposition stranding. Linguistic Inquiry 12, 55-91.

Langendoen, D. Terence \& Thomas G. Bever. 1973. Can a not unhappy man be called a not sad one? In Stephen R. Anderson \& Paul Kiparsky (eds.). A festschrift for Morris Halle, 392-409. New York: Holt, Rinehart and Winston.

Langendoen, D. Terence. 1979. The role of grammar in the use of language. In Doris Aaronson and Robert W. Rieber (eds.), Psycholinguistic research: Applications and implications, 229-40. Hillsdale, NJ: Lawrence Erlbaum Associates.

Myers, James. 2008. Syntactic judgment experiments. Language and Linguistics Compass 3, 406-23.

Niedersächsisches Wörterbuch. Ed. Dieter Stellmacher. Institut für Historische Landesforschung der Universität Göttingen, Arbeitsstelle Niedersächsisches Wörterbuch. Bd. 4: F/V. Bearbeitet von Ulrich Scheuermann. Neumünster: Wachholtz Verlag 1994.

Nunes, Jairo. 1995. The copy theory of movement and linearization of chains in the Minimalist Program. PhD dissertation, University of Maryland.

Nunes, Jairo. 2004. Linearization of chains and sideward movement. Cambridge, MA: MIT Press.

Nykiel, Joanna. 2010. Competence, performance and extra prepositions. Journal of English Linguistics 38, 143-66.

Ouhalla, Jamal. 2005. Clitic-placement, grammaticalization and reanalysis. In Guglielmo Cinque \& Richard Kayne (eds.), The Oxford handbook of comparative syntax. 607-38. Oxford: Oxford University Press.

Pesetsky, David. 2000. Phrasal movement and its kin. Cambridge, MA: MIT Press.

Pullum, Geoffrey K. 2007. Could preposition doubling be headed our way? Language Log, 15 May 2007. http://itre.cis.upenn.edu/ myl/languagelog/archives/004498.html, accessed on $10 / 07 / 2011$.

Radford, Andrew. 2009. Analysing English sentences. Cambridge: Cambridge University Press. 
Radford, Andrew. 2010a. Real relatives: The syntax of relative clauses in live radio and TV broadcasts. Paper presented at the Essex Which Hunt conference, 4 June 2010.

Radford, Andrew. 2010b. The syntax of wh-clauses in live radio and TV broadcasts. Paper presented at the Generative Grammar in the 21st Century conference, University of Essex, 7 July 2010.

Radford, Andrew \& Claudia Felser. 2011. On preposition copying and preposition pruning in wh-clauses in English. Essex Research Reports in Linguistics 60.2, Dept of Language and Linguistics, University of Essex.

Reintges, Chris H., Philip LeSourd \& Sandra Chung. 2006. Movement, wh-agreement and apparent $w h$-in-situ. In Lisa Cheng \& Norbert Corver (eds.), Wh-Movement: Moving on, 165-94. Cambridge, MA: MIT Press.

Rizzi, Luigi. 1990. Relativised minimality. Cambridge MA: MIT Press.

Sato, Mikako. 2007. Sensitivity to syntactic and semantic information in second language sentence processing. PhD dissertation, University of Essex.

Schütze, Carson. 1996. The empirical base of linguistics: Grammaticality judgments and linguistic methodology. Chicago: University of Chicago Press.

Sobin, Nicholas. 1997. Agreement, default rules and grammatical viruses. Linguistic Inquiry $28,318-43$.

Staum, Laura \& Ivan A. Sag 2008. Antilocality in ungrammaticality: Nonlocal grammaticality violations are easier to process. Poster presented at CUNY 2008 in Chapel Hill, NC.

Zwicky, Arnold M. 2002. I wonder what kind of construction that this example illustrates. In David I. Beaver, Louis D. Casillas Martínez, Brady Z. Clark \& Stefan Kaufmann (eds.), The construction of meaning, 219-48. Chicago: CSLI Publications.

\section{Appendix: List of experimental sentences}

(1) Games developers have created a world (in) which people truly want to lose themselves (in).

(2) Some architects design buildings (in) which nobody would ever want to live or work (in).

(3) Climate change is a topic (in) which many people have a very strong interest (in).

(4) An anti-tank missile hit the police post (in) which several suspects were being questioned (in).

(5) The journalist knew this was an area (in) which the Taliban were currently operating (in).

(6) The audience didn't enjoy the manner (in) which the bald comedian addressed them all (in).

(7) The judge didn't like the tone (in) which the teenage defendant spoke to her (in).

(8) The reporter commented on the predicament (in) which Newcastle's new manager unexpectedly found himself (in).

(9) Both teams were wearing colours (in) which we would expect them to be dressed (in).

(10) People like watching games (in) which you can't predict what's going to happen next (in).

(11) Obama was unhappy about the situation (in) which the democratic party now found itself (in).

(12) Everyone praised the stadium (in) which the opening game is scheduled to be played (in).

(13) IKEA only has ten stores in Britain (from) which they sell their famous furniture (from). 
(14) The rooftop was a position (from) which the sharpshooter could see the president easily (from).

(15) Spurs have only got sixteen players (from) which the manager can choose the team (from).

(16) The newspaper's legal experts only answer questions (about) which many people may have worries (about).

(17) The explosion in Beijing was an incident (about) which Chinese newspapers hadn't reported anything (about).

(18) The government introduced new legislation (about) which hardly any backbencher had previously heard anything (about).

(19) Nobody supported the club (for) which Wayne Rooney had also recently refused to play (for).

(20) A secret affair came to light (for) which the foreign secretary later apologised profusely (for).

(21) Sally found a diamond watch (for) which someone must have paid a small fortune (for).

(22) Richard recently joined a society (of) which his best friend was already a member (of).

(23) The teacher suggested a project (to) which almost all students wanted to contribute something (to).

(24) The new company offered alarm systems (on) which most customers felt they could rely (on). 